\title{
Excess dietary cholesterol may have an adverse effect on growth performance of early post-larval Litopenaeus vannamei
}

\author{
Jin Niu', Peng-Fei Chen², Li-Xia Tian², Yong-Jian Liü ${ }^{2 *}$, Hei-Zhao Lin ${ }^{1}$, Hui-Jun Yang ${ }^{2}$ and Gui-Ying Liang ${ }^{2}$
}

\begin{abstract}
One experiment was conducted to determine the nutritive value of cholesterol for post-larval shrimp, Litopenaeus vannamei. Four isoenergetic and isonitrogenous diets supplemented with four levels of cholesterol (D1, D2, D3 and D4 with $0,0.5 \%, 1 \%$ and $2 \%$ cholesterol, respectively) were fed to triplicate groups of L. vannamei shrimp (mean initial wet weight $0.8 \mathrm{mg}$ ) for 27 days. After the trial, shrimp fed the D1 diet had the best growth performance (final body weights: FBW; weight gain: WG; specific growth rate: SGR), while there was no significant difference between diet treatments with respect to survival. The whole body crude protein level in the shrimp decreased with the increase in dietary cholesterol levels, while the whole body crude lipid level in shrimps in the D4 diet treatment was significantly higher $(P<0.05)$ than in other diet treatments. Dietary analysis indicated that the D1 diet contained $0.92 \%$ cholesterol prior to supplementation, which may have satisfied the dietary cholesterol requirement of post-larval L. vannamei; excess dietary cholesterol may thus lead to adverse effects on the growth performance of post-larval shrimp.
\end{abstract}

Keywords: Cholesterol, Growth, Larvae, Lipid classes, Litopenaeus vannamei, Survival

\section{Background}

Litopenaeus vannamei is the most common shrimp cultured in the western hemisphere [1] and was introduced into China in 1988. It now is the dominant species in China, mainly cultured in the coastal regions in southern China, but larval shrimp breeding is still dependent on live prey, such as rotifers and Artemia. Live prey may be a source of diseases or parasites to the larval rearing system [2]. Furthermore, during the transfer from live prey to artificial diets, high mortality and poor growth of larval shrimp has consistently been observed [3]. The main constraint to the sustainable and healthy development of this species remains the lack of effective and commercially acceptable weaning and on-growing formulated diets. However, substitution of appropriate formulated

\footnotetext{
* Correspondence: edls@mail.sysu.edu.cn

${ }^{2}$ Nutrition Laboratory, Institute of Aquatic Economic Animals, School of Life Science, Sun Yat-sen University, Guangzhou 510275, People's Republic of China

Full list of author information is available at the end of the article
}

diets for live prey is crucial for sustaining production of consistently high quality juvenile $L$. vannamei.

An essential step in the development of formulated diet for larval shrimp is to define their nutrient requirements. Cholesterol is an essential precursor of bile acids, steroid hormones, molting hormones, vitamin $\mathrm{D}_{3}$ and prostaglandins, which are involved in the molting process in shrimp [4]. Most animals can synthesize sterols from acetate, but crustaceans, like other arthropods, are incapable of de novo sterol synthesis from acetate [5]. Therefore, dietary cholesterol is considered essential for good growth and survival of crustaceans. For example, Penaeus japonicus [6], larval P. japonicus [7], P. monodon [8] and Cherax quadricarinatus [9] fed a sterol-free /deficient diet had poor growth and survival. However, no research has yet been reported regarding the effects of cholesterol on growth performance of early post-larval L. vannamei. Therefore, the objective of the present study was to evaluate whether adding dietary cholesterol could improve the growth performance of early $L$. vannamei post-larvae. 


\section{Materials and methods}

\section{Diet preparation and dietary treatments}

Four artificial diets (D1, D2, D3, and D4) were prepared by supplementing cholesterol at $0,0.5 \%, 1 \%$ and $2 \%$ respectively, as shown in Table 1. Cholesterol (95\% purity) was purchased from Sigma (Sigma Chemical, St. Louis, MO, USA). Diet analysis indicated that the D1 diet already contained $0.92 \%$ cholesterol. The method of diet preparation was the same as described by Niu et al. [9]. Shrimps were acclimatized to the experimental conditions and fed a control diet (D1 without supplemented cholesterol) with a particle size of $300 \mu \mathrm{m}$ for 3 days before the start of the experiment. The particle size changed to $450 \mu \mathrm{m}, 600 \mu \mathrm{m}, 900 \mu \mathrm{m}$ and $1.2 \mathrm{~mm}$, from days 1 to 5,6 to 10,11 to 21 and 22 to 27 respectively. All diets were stored at $-20{ }^{\circ} \mathrm{C}$ prior to used.

\section{Experimental system}

A 27-day feeding trial was conducted in a recirculating water system. The system was the same as described by

Table 1 Ingredients and proximate composition of experimental diets (\% dry matter)

\begin{tabular}{|c|c|c|c|c|}
\hline Ingredients & D1 & D2 & D3 & D4 \\
\hline White fish meal & 50.75 & 50.75 & 50.75 & 50.75 \\
\hline Protein hydrolysate & 20 & 20 & 20 & 20 \\
\hline a-Starch & 5 & 5 & 5 & 5 \\
\hline Soybean oil & 3 & 3 & 3 & 3 \\
\hline Phospholipid (purity 97\%, pc-60) & 2 & 2 & 2 & 2 \\
\hline Vitamin premix ${ }^{1}$ & 1 & 1 & 1 & 1 \\
\hline Mineral premix ${ }^{2}$ & 4 & 4 & 4 & 4 \\
\hline Vitamin C & 0.65 & 0.65 & 0.65 & 0.65 \\
\hline Krill meal & 3 & 3 & 3 & 3 \\
\hline Beer yeast & 3 & 3 & 3 & 3 \\
\hline Cellulose & 2 & 1.5 & 1.0 & 0 \\
\hline Cholesterol (purity 95\%) & 0 & 0.5 & 1 & 2 \\
\hline Others $^{3}$ & 5.6 & 5.6 & 5.6 & 5.6 \\
\hline \multicolumn{5}{|l|}{ Proximate composition } \\
\hline Moisture & 7.30 & 7.27 & 5.84 & 5.09 \\
\hline Cholesterol & 0.92 & 1.32 & 1.80 & 2.75 \\
\hline Crude protein & 57.6 & 57.8 & 57.8 & 57.8 \\
\hline Crude lipid & 12.2 & 12.2 & 13.0 & 12.8 \\
\hline Ash & 17.0 & 17.0 & 17.1 & 17.0 \\
\hline
\end{tabular}

${ }^{1}$ Contents $(\mathrm{g} / 100 \mathrm{~g})$ retinyl acetate, 0.25 ; cholecalciferol, 0.625 ; all-rac-a -tocopheryl acetate, 7.5; menadione, 0.25; thiamin, 0.025; riboflavin, 0.1 $\mathrm{D}$-calcium pantothenate, 0.5 ; pyridoxine $\mathrm{HCL}, 0.075$; cyanocobalamin, 0.25 ; niacin, 0.25; folic acid, 0.025; biotine, 0.25; meso-inositol, 37.9; cellulose, 50 (Niu et al. 2008) [10].

${ }^{2}$ Contents (g/100 g) KCL, 9; Kl, 4 mg; NaCL, 4; $\mathrm{CuSO}_{4}-5 \mathrm{H}_{2} \mathrm{O}, 0.3 ; \mathrm{ZnSO}_{4}-7 \mathrm{H}_{2} \mathrm{O}$, 0.4; $\mathrm{CoSO}_{4}-7 \mathrm{H}_{2} \mathrm{O}, 2$ mg; $\mathrm{FeSO}_{4}-7 \mathrm{H}_{2} \mathrm{O}, 2 ; \mathrm{MnSO}_{4}-\mathrm{H}_{2} \mathrm{O}, 0.3 ; \mathrm{MgSO}_{4}-7 \mathrm{H}_{2} \mathrm{O}, 12.4$; $\mathrm{Ca}\left(\mathrm{HPO}_{4}\right)_{2}-2 \mathrm{H}_{2} \mathrm{O}, 50 ; \mathrm{CaCO}_{3}, 21.5$. (Niu et al. 2008) [10].

${ }^{3}$ Contents $(\mathrm{g} / 100 \mathrm{~g})$ : Sodium alginate, 3 ; Choline chloride, 1; Methionine, 1; Tryptophan, 0.6 .
Niu et al. [10]. During the trial, the diurnal cycle was $15 \mathrm{~h}$ light/9 h dark. Water quality parameters were recorded daily and were maintained as follows: salinity, 30 to $32 \mathrm{~g} / \mathrm{L}$; temperature, 27 to $29{ }^{\circ} \mathrm{C}$; dissolved oxygen, 5.6 to $6.2 \mathrm{mg} / \mathrm{L}$; ammonia-nitrogen, 0.05 to $0.07 \mathrm{mg} / \mathrm{L}$.

\section{Experimental shrimp, feeding and maintenance}

The shrimps used were obtained from Evergreen (Zhanjiang) South Ocean Science and Tech Co. Ltd, and the post-larvae were used just after metamorphosis from the mysid stage (15 days post-hatching). Shrimps were collected randomly and groups of 100 shrimps were weighed (following a $24 \mathrm{~h}$ fast) before being stocked into individual tanks. Initial average wet weight $(0.8 \mathrm{mg})$ was calculated by dividing the group weight by the number of shrimps. Three replicate tanks (with 1,000 shrimps initially in each tank) were used for each dietary treatment. Shrimps were fed the experimental diets 6 times daily (07:00, 10:00, 13:00, 16:00, 19:00 and 22:00 hours). Feeding quantity was adjusted so that shrimps were fed to slightly to excess. After 27 days of the feeding trial, shrimps were fasted for 24 hours and all surviving shrimps from each tank were weighed as a group. Final average weights were calculated by dividing the group weight by the number of shrimp. Survival was calculated by individually counting all surviving shrimps at the beginning of the experiment and again at the end.

\section{Sampling and chemical analysis}

After weighing, all shrimps in each tank were dried and ground for whole body composition and lipid analysis. Lipids were extracted from the whole body of shrimps with chloroform-methanol [11] and then further separated into neutral lipid and polar lipid fractions by SepPak silica cartridge (Waters, USA) [12]. Both fractions were analyzed for lipid classes using an Iatroscan (MK6, Mitsubishi Chemical Medience, Japan) at the Sun YatSen University of Madical Sciences. Lipid classes were identified by comparison with the appropriate standard (Sigma Chemical, St. Louis, MO, USA). Moisture, crude protein and ash of the experimental diets and shrimps were determined using standard methods of AOAC [13].

\section{Statistical analysis}

All data from triplicate tanks of each diet were analyzed using one-way analysis of variance and Duncan's multiple-range test. The software was SPSS (Version 10.0). Differences were considered significant at $P<0.05$.

\section{Results}

\section{Biological performance of shrimp}

Table 2 shows that survival was in the range of $81 \%$ to $87 \%$, and no significant difference was found between 
Table 2 Growth performance of shrimp fed a variety of experimental diets

\begin{tabular}{|c|c|c|c|c|c|}
\hline Cholesterol levels, \% & D10 & D20.5 & D31 & D42 & One way ANOVA ( $P$ value) \\
\hline \multicolumn{6}{|l|}{ Growth performance } \\
\hline Initial number & 1,000 & 1,000 & 1,000 & 1,000 & / \\
\hline IBW, mg & 0.8 & 0.8 & 0.8 & 0.8 & / \\
\hline Final number & $865.3 \pm 33.5$ & $806.3 \pm 49.3$ & $856.7 \pm 24.7$ & $853.7 \pm 10.7$ & 0.599 (ns) \\
\hline FBW, mg & $53.0 \pm 1.5^{\mathrm{a}}$ & $41.3 \pm 0.4^{b}$ & $35.3 \pm 4.1^{\mathrm{b}}$ & $33.5 \pm 3.8^{b}$ & 0.006 \\
\hline WG, \% & $6529 \pm 192^{\mathrm{a}}$ & $5058 \pm 44^{b}$ & $4308 \pm 514^{b}$ & $4092 \pm 480^{b}$ & 0.006 \\
\hline SGR, \%/day & $15.5 \pm 0.1^{\mathrm{a}}$ & $14.6 \pm 0.0^{\mathrm{ab}}$ & $14.0 \pm 0.4^{b}$ & $13.8 \pm 0.4^{\mathrm{b}}$ & 0.015 \\
\hline Survival, \% & $86.5 \pm 3.4$ & $80.6 \pm 4.9$ & $85.7 \pm 2.5$ & $85.4 \pm 1.1$ & 0.599 (ns) \\
\hline
\end{tabular}

Values are shown as mean \pm SE of three replicates. Means within the same row and not sharing a common superscript are significantly different (Ducans, $P<0.05$ ); ns, no significant difference detected $(P>0.05)$.

IBW (mg/shrimp): Initial body wet weight (mg/shrimp).

FBW (mg/shrimp): Final body wet weight ( $\mathrm{mg} /$ shrimp).

WG (\%): weight gain $=100 \times$ (final body weight- initial body weight)/initial body weight.

SGR (\%/day): specific growth rate $=100 \times($ In final wt.- In initial wt.)/total number of experimental days.

Survival $(\%)=100 \times($ final shrimp number)/(initial shrimp number).

the groups. Growth performance (FBW, WG and SGR) of shrimp fed the D1 diet was significantly higher than that of shrimp fed the other diets $(P<0.05)$. Moreover, no significant differences were found in growth performance (FBW, WG and SGR) among shrimp fed the D2, D3 and D4 diets $(P>0.05)$.

\section{Whole body lipid class of shrimp}

Table 3 shows that total lipid of shrimps fed the D4 diet was significantly higher than that of shrimps fed the other diets, and neutral lipid (NL) had the same tendency as the total lipid. The NL accumulation in whole body of shrimps was $(35.1 \pm 1.0) \%, \quad(36.2 \pm 3.0) \%$, $(37.7 \pm 1.7) \%$ and $(46.6 \pm 3.9) \%$ and corresponded with the retention of total cholesterol (TC) at $(20.9 \pm 0.3) \%$, $(22.4 \pm 2.8) \%,(23.3 \pm 1.3) \%$ and $(27.7 \pm 3.1) \%$ from the D1, D2, D3 and D4 diet treatments, respectively. The TC accumulation in shrimps fed the D4 diet was significantly higher than that of shrimps in the D1, D2 and D3 dietary treatment groups. The situation for polar lipids (PL) was exactly opposite to the situation for NL. The PL content of shrimps fed the D4 diet was significantly lower $(P<0.05)$ than that of shrimps fed the other diets. The major lipid class of NL fraction was TC, comprising more than $20 \%$ of total lipid, while in the PL fraction, phosphatidylcholine (PC) was the main component, comprising approximately $40 \%$ of total lipid.

\section{Whole body composition of shrimp}

Table 4 shows that crude protein levels in the whole body of shrimp decreased along with the increase in dietary cholesterol levels, while the crude lipid level in the whole body of shrimp fed the D4 diet was significantly higher $(P<0.05)$ than that of shrimp fed the other diets (D1, D2 and D3).

\section{Discussion}

Table 2 shows that the best growth performance (FBW, WG and SGR) of shrimps was found in the D1 diet treatment and the addition of more dietary cholesterol restricted the growth of early L. vannamei post-larvae. Dietary composition analysis showed that the basal diet (D1) contained $0.92 \%$ cholesterol, which may have satisfied the requirements of early $L$. vannamei post-larvae. This may be due to the use of krill meal as a dietary ingredient, as this is normally a good source of cholesterol. Moreover, due to the cannibalistic nature during the early stages of shrimp development, surviving shrimps may have obtained some cholesterol from consumption of dead shrimps. Sheen et al. [8] reported that diets containing less than $0.8 \%$ cholesterol improved growth and survival of P. monodon. Thongrod and Boonyaratpalin [14] reported that when the basal diet already contained $0.6 \%$ sterol, cholesterol supplementation led to adverse effects, such as retarded growth of banana shrimp, Penaeus merguiensis. Sheen [15] reported that mud crabs fed diets containing $0.5 \%$ and $0.79 \%$ cholesterol had significantly higher weight gain than those fed diets with either lower $(0.04 \%$ and $0.21 \%)$ or higher $(1.12 \%$ and $1.44 \%$ ) cholesterol levels, and that cholesterol levels higher than $1.12 \%$ had an adverse effect on mud crab growth. Sheen and D'Abramo [16] reported that the level of dietary lipids including phospholipids and cholesterol should be optimum and balanced in order to obtain maximum growth and survival of shrimps, and that high dietary lipid levels may have a detrimental effect on growth performance of crustaceans. Mercer [17] stated that physiological responses to nutrients were graded and produced a characteristic nutrient-response curve, which increased to a point and then tended to level off. The high levels of dietary cholesterol (D2, D3 and D4) which caused the negative growth response in this study 
Table 3 Total lipid and lipid class of whole body shrimp fed experimental diets

\begin{tabular}{|c|c|c|c|c|c|}
\hline Cholesterol levels, \% & D10 & D20.5 & D31 & D42 & One way ANOVA ( $P$ value $)$ \\
\hline \multicolumn{6}{|l|}{ Lipid composition } \\
\hline Total lipid ${ }^{1}$ & $1.6 \pm 0.1^{b}$ & $1.7 \pm 0.1^{b}$ & $1.7 \pm 0.1^{b}$ & $2.2 \pm 0.1^{\mathrm{a}}$ & $<0.001$ \\
\hline Neutral lipid² & $35.1 \pm 1.0^{\mathrm{b}}$ & $36.2 \pm 3.0^{\mathrm{b}}$ & $37.7 \pm 1.7^{\mathrm{b}}$ & $46.6 \pm 3.9^{\mathrm{a}}$ & 0.008 \\
\hline TC & $20.9 \pm 0.3^{b}$ & $22.4 \pm 2.8^{b}$ & $23.3 \pm 1.3^{b}$ & $27.7 \pm 3.1^{\mathrm{a}}$ & 0.043 \\
\hline TG & $0.7 \pm 0.03$ & $0.6 \pm 0.02$ & $0.7 \pm 0.04$ & $0.7 \pm 0.02$ & 0.986 (ns) \\
\hline FFA & $9.3 \pm 0.2^{c}$ & $11.7 \pm 0.5^{b}$ & $14.8 \pm 1.1^{\mathrm{a}}$ & $16.2 \pm 0.2^{\mathrm{a}}$ & $<0.001$ \\
\hline Polar lipid & $64.9 \pm 1.1^{\mathrm{a}}$ & $63.8 \pm 3.0^{\mathrm{a}}$ & $62.3 \pm 1.7^{\mathrm{a}}$ & $53.4 \pm 3.9^{b}$ & 0.009 \\
\hline PC & $40.4 \pm 0.5$ & $40.6 \pm 1.0$ & $40.1 \pm 1.3$ & $37.0 \pm 1.4$ & 0.153 (ns) \\
\hline$P E$ & $14.6 \pm 0.2^{\mathrm{a}}$ & $12.5 \pm 1.1^{\mathrm{ab}}$ & $10.7 \pm 0.3^{b}$ & $8.5 \pm 0.6^{c}$ & 0.001 \\
\hline Pl & $0.52 \pm 0.02$ & $0.49 \pm 0.01$ & $0.53 \pm 0.03$ & $0.52 \pm 0.05$ & 0.835 (ns) \\
\hline Others & $9.4 \pm 0.5$ & $10.2 \pm 1.3$ & $11.1 \pm 0.6$ & $7.4 \pm 2.1$ & 0.311 (ns) \\
\hline
\end{tabular}

Values are shown as means \pm SE of three replicates. Means within the same row and not sharing a common superscript are significantly different (Ducans, $P<0.05)$; ns, no significant difference detected $(P>0.05)$.

$\mathrm{TC}=$ total cholesterol; $\mathrm{TG}=$ triglycerides; $\mathrm{FFA}=$ free fatty acids; $\mathrm{PC}=$ phosphatidylcholine; $\mathrm{PE}=$ phosphatidylethanolamine; $\mathrm{PI}=$ phosphatidylinositol.

$1 \%$ Wet weight.

${ }^{2} \%$ Total lipid.

may be a nutrient-response characteristic rather than toxicity. The results of this study provide further confirmation that an appropriate dietary cholesterol level is important because high dietary sterol levels may retard growth in crustaceans.

Table 3 shows the concentrations of various classes of lipids in the whole body of shrimps fed diets with and without cholesterol supplementation. The NL accumulation in the whole body of shrimps fed the D4 diet was significantly higher than that of shrimps fed the other diets, and TC accumulation had the same tendency as NL accumulation. This suggests that TC, as the major component of NL was directly influenced by the dietary cholesterol levels, which increased with the increasing amount of dietary cholesterol. Free fatty acids (FFA) accumulation in the whole body of shrimps increased with an increasing amount of dietary cholesterol, although the physiological mechanisms behind this have not been clarified. The situation for PL was exactly the opposite to that of NL. The PL content of shrimps fed the D4 diet was significantly lower than that of shrimps fed the other diets. The major lipid classes of the NL and PL fractions were $\mathrm{TC}$ and $\mathrm{PC}$, respectively, and it was TC rather than PC that was influenced by dietary cholesterol levels.

Table 4 shows the whole body composition of shrimps fed diets with and without cholesterol supplementation. The crude lipid content of shrimps fed the D4 diet was significantly higher $(P<0.05)$ than that of shrimp fed the other diets, while the crude protein contents of shrimps decreased with the increase of dietary cholesterol levels. In the study of Sheen [15], both the crude lipid and crude protein levels in the whole body tissue increased with increasing level of dietary cholesterol from $0.21 \%$ to $0.79 \%$, then decreased as the level of dietary cholesterol rose to $1.12 \%$ and $1.44 \%$. It has been reported that cod larvae may have limited ability to digest neutral lipids [18]. If this is also the case in shrimps, excess addition of dietary cholesterol as neutral lipid may reduce the digestible energy content and lead to an increase in diet consumption in order to use protein as the source of energy. It can therefore be hypothesized that the excess dietary cholesterol was deposited as body lipid, which induced increased dietary protein consumption as a source of energy for growth, but not for body protein deposition.

Table 4 Whole body composition (\% wet weight) of shrimp fed experimental diets

\begin{tabular}{lllllr}
\hline Cholesterol levels (\%) & D10 & D20.5 & D31 & D42 & One way ANOVA (P value) \\
\hline Whole body composition & & & & & \\
Moisture & $79.7 \pm 0.4$ & $80.5 \pm 0.6$ & $79.6 \pm 0.7$ & $79.7 \pm 1.3$ & 0.507 (ns) \\
Protein & $17.9 \pm 0.1^{\mathrm{a}}$ & $17.5 \pm 0.3^{\mathrm{b}}$ & $15.7 \pm 0.1^{\mathrm{c}}$ & $15.2 \pm 0.1^{\mathrm{d}}$ & $<0.001$ \\
Lipid & $1.6 \pm 0.1^{\mathrm{b}}$ & $1.7 \pm 0.1^{\mathrm{b}}$ & $1.7 \pm 0.1^{\mathrm{b}}$ & $2.2 \pm 0.1^{\mathrm{a}}$ & $<0.001$ \\
Ash & $3.9 \pm 0.1^{\mathrm{b}}$ & $3.9 \pm 0.1$ & $4.0 \pm 0.1$ & $4.0 \pm 0.1$ & 0.431 (ns) \\
\hline
\end{tabular}

Values are shown as means \pm SE of three replicates. Means within the same row and not sharing a common superscript are significantly different (Ducans, $P<0.05)$; ns, no significant difference detected $(P>0.05)$. 


\section{Conclusions}

In conclusion, the present results show that the level of dietary cholesterol should be strictly controlled; the basal diet already contained $0.92 \%$ cholesterol, which may have satisfied the requirement of early $L$. vannamei larvae. Further dietary cholesterol supplementation was detrimental for larval shrimp development.

\section{Abbreviations}

FBW: Final body weight; WG: Weight gain; SGR: Specific growth rate; NL: Neutral lipid; TC: Total cholesterol; PL: Polar lipid; PC: Phosphatidylcholine; FFA: Free fatty acids; PE: Phosphatidylethanolamine; PI: Phosphatidylinositol.

\section{Competing interests}

The authors declare that they have no competing interests.

\section{Acknowledgements}

This research was supported by Fund of National Modern Industrial Technology System of Shrimp (nycytx-46); Special Scientific Research Funds for Central Non-profit Institutes, South China Sea Fisheries Research Institute, Chinese Academy of Fishery Sciences (2009TS29, 2010YD02, 2010TS04 and 2011YD01); the Project of Science and Technology of Guangdong Province (2011A020202007); the Project of Key Science and Technology of Hainan Province (ZDXM20100028); and the State 863 Project (2012AA10A409).

\section{Author details}

${ }^{1}$ Key Laboratory of Aquatic Product Processing, Ministry of Agriculture, South China Sea Fisheries Research Institute, Chinese Academy of Fishery Science, Guangzhou 510300, People's Republic of China. ${ }^{2}$ Nutrition Laboratory, Institute of Aquatic Economic Animals, School of Life Science, Sun Yat-sen University, Guangzhou 510275, People's Republic of China.

\section{Authors' contributions}

JN carried out the experiments and drafted the manuscript. JN and PFC performed the statistical analysis. LXT, HJY HZL and GYL participated in the design of the study. YJL conceived the study, and participated in its design and coordination. All authors read and approved the final manuscript.

Received: 12 March 2012 Accepted: 25 June 2012

Published: 25 June 2012

\section{References}

1. Rosenberry B: World Shrimp Farming. Number 12. San Diego, California: Shrimp News International; 2000.

2. Planas $M$, Cunha I: Larviculture of marine fish: problems and perspectives. Aquaculture 1999, 177:171-190.

3. Bengtson DA, Léger P, Sorgeloos P: Use of Artemia as a food source for aquaculture. In Artemia Biology. Edited by Browne RA, Sorgeloos P, Trotman CNA. Boca Raton, FL: CRC Press; 1991:255-285.

4. Akiyama DM, Dominy WG, Lawrence AL: Penaeid shrimp nutrition. In Marine Shrimp Culture: Principles and Practices. Edited by Fast AW, Lester $\amalg$. New York: Elsevier Science Publishing; 1992

5. Fox C, Brown J, Briggs M: The nutrition of prawns and shrimp in aquaculture, a Review of Recent Research. In Recent Advances in Aquaculture. vol. V. Edited by Muir JF, Roberts RJ. Oxford, England: Blackwell Scientific Publications; 1994.

6. Kanazawa A, Teshima S, Tokiwa S, Endo M, Abdel Razek FA: Effect of shortnecked clam phospholipid on the growth of prawn. Bull Jpn Soc Sci Fish 1979, 45:961-965.

7. Teshima S, Kanazawa A: Effect of several factors on growth and survival of the prawn larvae reared with microparticulate diets. Bull Jpn Soc Sci Fish 1983, 49:1893-1896.

8. Sheen SS, Liu PC, Chen SN, Chen JC: Cholesterol requirement of juvenile tiger shrimp (Penaeus monodon). Aquaculture 1994, 125:131-137.

9. Hernándeza PV, Olvera-Novoab MA, Rousec DB: Effect of dietary cholesterol on growth and survival of juvenile redclaw crayfish Cherax quadricarinatus under laboratory conditions. Aquaculture 2004, 236:405-411.
10. Niu J, Liu YJ, Tian LX, Mai KS, Yang HJ, Ye CX, Gao W: Effect of dietary phosphorus sources and varying levels of supplemental phosphorus on survival, growth and body composition of larval shrimp (Litopenaeus vannamei). Aquacult Nutr 2008, 14:472-479.

11. Folch J, Lees M, Stanley GHS: A simple method for the isolation and purification of total lipides from animal tissues. J Biol Chem 1957, 226:497-509.

12. Juaneda A, Rocquelin G: Rapid and convient separation of phospholipid and non phosphorus lipids from rat heart using silica cartridges. Lipids 1985, 28:40-41.

13. AOAC: Official Methods of Analysis. 16th edition. Washington, DC Association of Official Analytical Chemists; 1990.

14. Thongrod S, Boonyaratpalin M: Cholesterol and lecithin requirement of juvenile banana shrimp, Penaeus merguiensis. Aquaculture 1998, 161:315-321.

15. Sheen SS: Dietary cholesterol requirement of juvenile mud crab Scylla serrata. Aquaculture 2000, 189:277-285.

16. Sheen SS, D'Abramo LR: Response ofjuvenile freshwater prawn, Macrobrachium rosenbergii, to different levels of a cod liver oil/corn oil mixture in a semi-purified diet. Aquaculture 1991, 93:121-134.

17. Mercer LP: The quantitative nutrient-response relationship. J Nutr 1982, 112:560-566.

18. Olsen RE, Henderson RJ, Pedersen T: The influence of dietary lipid classes on the fatty acid composition of small cod Gadus morhua L. juveniles reared in an enclosure in northern Norway. J Exp Mar Biol Ecol 1991, 148:59-76.

doi:10.1186/2049-1891-3-19

Cite this article as: Niu et al.: Excess dietary cholesterol may have an adverse effect on growth performance of early post-larval Litopenaeus vannamei. Journal of Animal Science and Biotechnology 2012 3:19.

\section{Submit your next manuscript to BioMed Central and take full advantage of:}

- Convenient online submission

- Thorough peer review

- No space constraints or color figure charges

- Immediate publication on acceptance

- Inclusion in PubMed, CAS, Scopus and Google Scholar

- Research which is freely available for redistribution 